\section{Why another journal?}

In recent years, we have seen the advent of new psychological journals, and the future will bring forth more. In most cases, these journals represent emerging areas of specialization, although they also add to the overall number of pages available for publication, thus helping to keep publication outlets in pace with the ever increasing volume of research. In all instances, however, the function of the journals is archival: It is to provide a permanent record for future generations of scholars'. Being archival, they are published at the leisurely pace of letter-press methods, often with additional lags induced by budget limitations of the sponsoring society or press.

Years ago, when both the volume of publication and the size of scientific meetings was smaller, archival publication was sufficient. At that time, the scientist need not wait for such publication to know what was going on. By going to two or three meetings a year, he could hear virtually all research papers in which he was interested, talk if need be with their authors, and keep abreast of research in his field as it was being done. With larger volumes of research being carried out at more institutions throughout a larger geographical area and presented at increasingly larger meetings, this informal means of rapid communication has become less and less adequate. This conclusion was reached, and spelled out in some detail, by the Board of Scientific Affairs of the American Psychological Association in 1959. One remedy the board proposed, was to found a journal that would publish brief reports of research with a very short publication lag.

This writer has always been impressed with this argument, but no concrete action on it has ever been taken. In the meantime, careful studies of communication in psychology currently being reported by the APA Panel on Information Exchange show even more convincingly the need felt by many psychologists for the more rapid communication of research. The mimeographed paper has often been used, and will continue to be used, to fill the gap, but it fails to reach all those who are interested. Moreover, it requires both a mimeograph machine and the willingness to use it; some scientists have neither. Some more systematic means of making available to all interested parties the results of research recently completed seems to be needed. That, at any rate, is the assumption on which this new journal is based.

\section{Type of artieles}

Another assumption is that articles published rapidly for current informal communication should be brief. For this, there are several reasons. One lies in the mechanics of publishing; short articles, obviously, cost less to publish and can be processed atgreater speed than longer ones. Another is that a journal of this sort is not intended to compete in function with the archival journals, even though in some instances a brief article is all that ever need be published. A third reason is to save the reader; if readers are to keep up with current research, they can read more short articles than they can long ones. Finally, we have in mind the collector of reprints; short articles can be so designed that a reader can tear out the articles in which he is interested and file them along with his reprints. On the other hand, for those authors who wish to distribute reprints and those readers who wish to keep their journals intact and to procure separate reprints, we are providing all authors of articles in this journal with 100 free reprints and the opportunity to buy additional ones if they desire.

With these considerations in mind, we have set a limit of 1200 words or its equivalent in tables and illustrations for articles to be published in the journal. This is the same limit used by the journal SCIENCE and has proved to be a practical size for describing fairly adequately any individual experiment or study. It would be desirable for all articles to come as close as possible to this limit, but we will use "white space" where necessary to enable us always to publish an article on the two sides of one page.

\section{Name of the journal}

Why did we choose the name PSYCHONOMIC SCIENCE for this endeavor? The name SCIENCE was chosen both because our policy on the length of articles is like that of the journal SCIENCE and because we wish to emphasize that the journal will publish only rigorous scientific research 
as distinguished from clinical studies or professional articles. The term PSYCHonomIC was chosen, as it was recently by a new society, because it is the word in the unabridged dictionary that comes closest to meaning "laws of behavior." The term implies basic science, as contrasted with applied or clinical science, and that is the kind of science the journal will cover. We conceive of the relation of psychonomy to applied psychology as much like that of physics to engineering or of physiology to medicine. Naturally, there is no sharp dividing line, but in choosing a name we have tried to define our editorial policy in the acceptance and publication of articles.

\section{Editorial review}

In order to gain speed in publishing, we shall sacrifice as a regular practice the detailed editorial review usually given articles by the major scientific journals. Many articles will be published after only a review by the Editor. We have, however, made arrangements with some consultants for an expeditious review where it seems warranted. Such a review should not add more than a week to publication lag, and that only in certain cases. We realize that in doing things this way we shall make mistakes. Articles will be published prematurely or with flaws that the expert would quickly detect. In some instances, because the articles are short, no one will be able to tell whether flaws exist.

This, we reason, is part of the price to be paid for rapid, informal communication. There are also some partial remedies. We encourage authors to have available lengthier versions of their articles and to indicate that these will be sent to interested readers on request. In addition, we shall reserve one section of the journal for CоMMENTS by readers. In this, we shall publish comments and criticisms about articles when they are stated succinctly and objectively.
If readers respond promptly after reading an article, it will usually be possible to publish these comments in the very next issue of the journal. СоMмENTS will be indexed annually along with the articles to which they refer, so that readers may find and read both.

\section{Publishing procedures}

To achieve rapid publication we are using a combination of photographic methods for headings and illustrations, cold-type composition, and photo-offset printing. The final product does not look quite as nice as letter-press composition and printing, but it is fully as readable and as usable. Printing requires about two weeks. All the rest of the work is done in the editorial office. Our schedules are set up so that the lag between the acceptance of an article and its publication should average about one month.

The plan is to publish twelve monthly issues, each containing 32 pages which, in this case, means 16 articles. To maintain rapid publication, however, the plan must remain flexible. Issues will be made larger or smaller, depending on the number of manuscripts to be published. If the total number of articles is larger than we estimate, issues will appear more frequently than monthly. If, after a year or more, the number is substantially larger, we plan to divide the journal into sections and permit readers to subscribe to the section that interests them most.

Information concerning subscriptions may be found on the inside of the front cover. Information for authors is given on the inside of the back cover.

\section{Reference}

BOARD OF SCIENTIFIC AFFAIRS, American Psychological Association. Technical communication in psychology: A statement of the problem.Amer. Psychol., 1959, 14, 267-271. 